\title{
Clinical Trial Regulatory Approval Documentation
}

National Cancer Institute

\section{Source}

National Cancer Institute. Clinical Trial Regulatory Approval Documentation. NCI

Thesaurus. Code C115665.

Records pertaining to the regulatory approval of a clinical trial. 